\title{
METHODOLOGY OF TRAINING PHYSICAL QUALITIES
}

\author{
Jumanov O.S.
}

Associate Professor, Physical Education And Sports Professionals Institute Of Retraining And Advanced Training, Uzbekistan

\section{ABSTRACT}

This article is about the methodology of improving physical qualities, changes in physical performance, the role of physical qualities in the life of a spiritually mature person, the effects of physical qualities on the body and the methods and analysis used in training.

KEYWORDS:- Physical education, speed, endurance, agility, joint mobility, and muscle flexibility, spiritual qualities, muscle tension.

\section{INTRODUCTION}

Each body has different levels of strength, speed, endurance, agility, joint mobility, and muscle flexibility. It is accepted to call them the qualities of the motion of the human body. Existing physical education systems are evaluated on the basis of the degree to which the human body is able to cultivate the qualities of movement.

Depending on the level of how to display these qualities, a person is described as strong, agile, agile, agile, etc., according to his level of physical fitness (energy). These qualities have their own characteristics that can be measured. They are called indicators of physical fitness, and the results of these indicators determine a person's readiness for creative work and defense of the homeland.

For example, if a trainer can sit on a $100 \mathrm{~kg}$ barbell on his shoulder only 3 times, another can sit more than 5 times with the same weight. The strength quality of the latter is assessed as improved because the exercise is performed more than twice. The level of strength, speed, etc. depends not only on the development of bones, muscles and other organs of the body, tissues, cells, etc., but also on the development of the spiritual qualities of the individual. Therefore, the training of the qualities of movement is closely connected with the work of cultivating the spiritual qualities and serves as a tool for this direction of education.

Striving to cultivate and develop the qualities of movement is an age-old dream of mankind. The effectiveness of the use of tools, military equipment and weapons depends on the qualities of the body, which nature has given to man and can be developed in the process of upbringing.

The main requirement of our time is to bring up a physically fit, morally pure, aesthetically pleasing, faithful, loyal, and well-versed in the modern foundations of technical science, comprehensively spiritually mature person, which complements the goals and objectives of 
CURRENT RESEARCH JOURNAL OF PEDAGOGICS 2(10): 108-112,

October 2021 DOI: https://doi.org/10.37547/pedagogics-crjp-02-10-21

ISSN 2767-3278

(C)2021 Master Journals

\section{Crossref do) 81 Google}

Accepted $26^{\text {th }}$ October, 2021 \& Published $31^{\text {th }}$ October, 2021

the country's physical education system.

The quality of power movement and the methodology of its development. Our body exhibits a quality called strength to overcome external influences or resistance.

The performance of an external motor activity through the action of an anti-impact muscle strain is related to a person's strength, a quality known as his or her strength ability.

The static position of the body changes when the practitioner tries to move the sports projectile (in throwing, etc.) while his body is at rest, - to rotate, move, lift, or vice versa, when an external force acts on his body, wrists. , but the practitioner tries to maintain his state until his exposure begins. This demonstrates the overcoming of external resistance.

As a scientific concept, an individual's capacity for power must have a clear definition and be distinguished from other behavioral qualities:

1) The force as a mechanical characteristic of motion is defined as "the effect of the force" $F$ "on the body of mass" M ";

2) Power in the form of physical qualities in the human body (for example, "increasing with age, increasing the strength of the athlete compared to those who do not do sports ...", etc.). In other words, it is defined as the ability to overcome or resist external resistance due to muscle tension.

In fact, muscle tension depends on the following physiological processes:

1) stresses associated with the frequency of movements from the center to the muscles (the higher the frequency, the greater the tension of the muscle and the greater the tension);

2 ) the number of units of motion added to the voltage;

3) The quality and level of tension is expressed by the amount and quantity of muscle excitability and the source of energy in it.

Demonstration of muscle strength (tension) is carried out in three different modes:

a) Muscle tension does not change its length (static, isometric). Demonstrate the ability to hold the body or parts of it in different positions (poses);

endurance (myometric) stress due to the reduction of muscle length. The tension is the same, it does not change, it occurs due to the phases of muscle contraction in cyclic and elastic movements;

b) During the stretching of a muscle, a force is created due to its elongation (flexion, relaxationpliometric). This force is manifested by the contraction of the muscles during sitting, throwing, and depressing.

It is accepted that the force of endurance, concession, and relaxation is called dynamic force.

The magnitude of the maximum force varies in different conditions. The variety of power demonstrations noted was accepted as a classification of power ability.

Quality of agility and methods of its development. Speed is one of the physical qualities of the human body as part of physical fitness.

Speed is a set of functional properties that characterize the speed of the actions of an individual or parts of his body, mainly the time of the reaction.

Speed is a complex quality of movement of the human body that does not manifest itself in isolation, so it is more accurate to think that it is a manifestation of the qualities of speed.

There are several ways in which speed can be expressed:

1. Individual movement speed (by overcoming 
CURRENT RESEARCH JOURNAL OF PEDAGOGICS 2(10): 108-112,

October 2021 DOI: https://doi.org/10.37547/pedagogics-crjp-02-10-21

ISSN 2767-3278

(C)2021 Master Journals

\section{Crossref doi) gr Google}

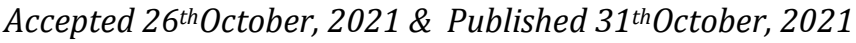

small external resistance).

2. Frequency of movements.

3. Speed of action reaction (latent latent period).

4. The pace of movement.

Those who do not have enough speed of movement have difficulty in mastering new movements (whether it is a vital necessity, work or professional activity) to get their hadith. The manifestation of this quality is physiologically related to the ability to conduct excitation impulses in nerve fibers, the rate of muscle contraction, and most importantly the rate of temporal communication of the necessary centers in the cerebral cortex. For example, the result of running $100 \mathrm{~m}$ depends on the time of the start-up reaction, the speed of individual movements (depressing, the speed of steps to quickly recover the number), and so on.

Agility and methods of its upbringing. Currently, the term "agility" is being replaced by the term "adaptive capabilities", and it is recommended to use the terms "adaptability" and "adaptive capacity".

Although these concepts are similar in meaning, they are not the same in content

"The word' conformity 'can serve as a starting point to define the concept of adaptive capacity (derived from the Latin word coordination, which means coordination, adaptation, regulation).

As for the concept of "coordination of actions", its meaning is much broader than the Latin translation. There are currently several definitions of action compatibility. All of them reveal some special aspects of this complex phenomenon (physiological, biomechanical, neurophysiological, cybernetic).

Agility - in a number of literature on the theory and methodology of physical culture (LPMatveev, VMZatsiorsky, SVYananis, etc.) to master the necessary actions of parts of the body, systems in order to acquire vital, professional skills It is recommended to look at it as an aspect of quick adaptation.

The ability to adapt quickly, in a short period of time, depending on the situation, is called agility.

In order to cultivate agility, the previously learned system of actions is replaced by new movements, and other elements are added to the learned movement. This, in turn, provides a high level of "creative" activity of the cerebral cortex. This process includes training, fitness training, healthy lifestyle physical education, basketball, volleyball, handball, football, gymnastics, athletics, jumping and throwing, water sports, and more.

We need to know the simplest teaching methods used to develop agility. They are:

- Performing a sound, an act of movement or movement agreed upon in response to a sound after the muscles have been sufficiently "relaxed";

- climbing or running down different heights, overcoming various obstacles (artificial, natural), intricate serpentines;

- Agility is developed in a complex, not in isolation, but in combination with other qualities, and the use of game, competition methods gives good results.

Endurance and methods of its development. Endurance is the ability to perform an action or an act of action in a defined manner, without diminishing its effectiveness over a long period of time.

The quality of this movement is divided into "general" and "special" endurance.

Endurance is mainly developed with lowintensity, long-term, more cyclical exercises.

They are: walking, running, cycling, swimming, 
CURRENT RESEARCH JOURNAL OF PEDAGOGICS 2(10): 108-112,

October 2021 DOI: https://doi.org/10.37547/pedagogics-crjp-02-10-21

ISSN 2767-3278

(C)2021 Master Journals

\section{Crossref doi) 81 Google}

Accepted $26^{\text {th }}$ October, 2021 \& Published $31^{\text {th }}$ October, 2021

rowing and more. The intensity, length of the rest interval, the use of the nature of the rest (active or passive rest), the number of repetitions of the exercise and other components will need to be considered.

Exercise to develop endurance can be achieved mainly by exercising when the body is feeling a little tired.

Those who are considered to be resilient are recognized as those who have a high level of performance. They are "aerobic" - that is, when our body is working, it is doing physical work by delivering enough oxygen to its organs.

In contrast, those who perform physical or professional activities without adequate oxygen supply to the working organ, and those who work in the absence of oxygen, also show a certain level of endurance (sprinters, breathing workers, etc.). . In them, physical activity is limited by the intensity of the heart rate (HR).

If resistance is improved in the anaerobic state, the maximal oxygen demand (MCI) should be 150-180 beats per minute. Ignorance of the ICC can have negative consequences, especially for students in colleges, academic lyceums and gymnasiums.

Flexibility and methods of its development. Flexibility is the quality of movement, which depends on the morphofunctional properties of the musculoskeletal system. These properties are observed and measured by the mobility of these hardware units, its maximum amplitude (deflection), bending, bending, elongation, flexibility, torsion, and so on.

Flexibility can be active or passive. Flexibility due to muscle force is called passive flexibility due to active flexibility, external resistance, inertia or weight, external force, and so on.

Active flexibility is directly related to muscle strength. However, strength training can weaken and limit mobility in the joints. But such negative effects can be overcome. Normalizing the quality of this movement can be achieved by combining exercises that develop flexibility and strength.

In conclusion, the importance and importance of physical education, especially the development of physical qualities, is obvious in the process of education. Because their development requires interdependence. But a certain type of sport requires a stronger form of movement. Other qualities are also relatively developed, but they can play the role of auxiliary, auxiliary action quality.

For example, basketball is considered to be a means of developing agility and endurance, while agility is considered to be a means of developing speed. In fact, the sport of basketball is basically the main means of cultivating endurance movement quality.

In weightlifting, strength is the leading quality. Exercising a lot of "jerking" (rivok) improves speed. In practice, we see that endurance and flexibility also develop as an auxiliary physical quality through these exercises.

The quality of any action is focused on solving a task called a specific action task. For example, jumping as high as possible, catching the ball, cheating an opponent, lifting a barbell, and so on.

The complexity of the movement task fosters the coordination of movements, creating the need for coherence of actions performed simultaneously and sequentially.

\section{ReFERENCES}

1. I.A. Karimov. Let's not deviate from the path of the great goal. Tashkent "Uzbekistan" 1993.

2. A.D.Navikov, L.P.Matveev. Theory and methods of physical education. Tashkent "Teacher" 1974. 
CURRENT RESEARCH JOURNAL OF PEDAGOGICS 2(10): 108-112,

October 2021 DOI: https://doi.org/10.37547/pedagogics-crjp-02-10-21

ISSN 2767-3278

(C)2021 Master Journals

Crossref doi) 81 Google

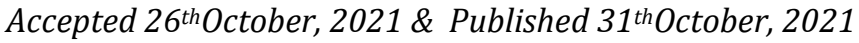

3. V.M. Kachashkin. Methods of physical education. Tashkent "Teacher" 1982.

4. A.Abdullaev, Sh.Khonkeldiev Theory and methods of physical education, Tashkent, 2005

5. A.Abdullaev and others. Extracurricular activities from physical education.

Tashkent, 2009. 